\title{
Getting to the heart of the matter:
}

\section{Examining the efficacy of a whole-school approach to behaviour management}

\author{
Bridget Scott \\ Special Education Advisor, Group Special Education, Christchurch
}

\begin{abstract}
This article reviews literature on whole-school approaches to behaviour management in order to address these questions: How is a whole- school approach to behaviour management defined in the literature? What are the key principles that make a whole-school approach effective? What are the key systems that make a whole-school approach effective? Is the involvement of students an important aspect of a whole-school approach? The review highlights current work on belonging, which shows that a person's sense of belonging has an impact on their engagement and therefore achievement in a school setting. For a whole-school approach to be effective it must have a positive impact on the engagement of the students. The findings of this review suggest that schools implementing a whole-school approach must first examine the quality of the relationships within their school as these have an impact on students' experiences of belonging. The principles and values about relationships that a school holds will shape the kind of whole -school approach they develop.
\end{abstract}

\section{KEYWORDS:}

Behaviour management, school behaviour, school culture, whole-school approach, school based intervention.

\section{INTRODUCTION}

Schools play a crucial role in shaping young people's futures. It is the ongoing social interactions that enable children to learn about themselves and how to become accepted and competent members of their social worlds (Wentzel, 1999). The way in which a school manages its students will have an impact on their sense of belonging, their level of engagement and their achievements (Osterman, 2000).

The school is at the heart of the future of the community. It is in the schools where children grow in knowledge, morality, their abilities to relate to others, their concepts of community and the ability to live life to the full. It is in the schools that the future of our societies gains formation and direction. (McAdam \& Lang, 2003, p. 50)

Effective behaviour management is an important factor in creating positive learning communities (Nelson, Martella, \& Marchand-Martella, 2002). Some schools struggle to meet the needs of students with severe and challenging behaviours. While these students generally make up a small percentage of a school population, addressing their needs can require a large amount of school time and resources (Hayden, 1997; Prochnow, 1998). They are also more likely to experience dropout, academic failure, criminal activity, unemployment and other negative outcomes (Eber, Sugai, Smith, \& Scott,
2002; Hayden, 1997). Many school behaviour programmes are reactive and have progressive steps in response to students' behaviour (Doig, 2000; Sugai \& Horner, 2000). Exclusion, which is often the ultimate intervention for students with emotional/behavioural and learning difficulties, alienates the students from their peers and their school community (Hayden, 1997). Children and adolescents who experience alienation from school often become adults who are socially alienated and experience poverty, political powerlessness, debt and criminal involvement (Hayden 1997; Orlemans \& Jenkins, 1998).

Many schools attribute causes of behaviour difficulties or disengagement to individual students (Certo, Cauley, \& Chafin, 2003; Prochnow, 1998; Thomson, 1999). They see something, for example a syndrome within the child such as ADHD, Aspergers, or, something in the child's environment as being the cause of the behaviour and interventions are planned accordingly. This places the burden on the individual rather than on the school culture and organisation. Behaviour should be viewed as a whole school issue requiring a wholeschool solution (Prochnow, 1998; Thomson, 1999).

The literature reviewed in this article shows that wholeschool behaviour approaches are being used by some schools in the UK, US, Australia and NZ (Doig, 2000; Eber et al., 2002; Gaffney, McCormack, Higgins, \& Taylor 2004; Hayden, 1997; McCurdy, Mannella, \& Eldridge, 2003; Nelson et al., 2002; Parsons, 2002; Prochnow, 1998; Sugai \& Horner, 2002; Thomson, 1999). Hayden (1997) points to a conflict in the literature citing Learmonth as linking whole-school behaviour approaches with a decrease in exclusions while Peagram is reported as suggesting that whole-school behaviour approaches can be linked with an increase in exclusions. Hayden concludes that the way in which school policies are implemented impacts on their effectiveness. The purpose of this literature review is to examine what has been learnt elsewhere to see what makes a whole-school behaviour approach effective. It asks the following questions:

- How is a whole-school approach defined in the literature?

- What are the key principles that make a whole-school approach effective?

- What are the key systems that make a whole school approach effective?

- Is the involvement of students in decision making an important aspect of a whole school approach? 


\section{Characteristics of New Zealand schools: A New Zealand context}

Suspensions and stand downs in New Zealand schools have increased from around 10, 000 in 1996 to 22,000 in 2002 (Hancock \& Trainor, 2004). Māori students and male students are over represented in the statistics (Collin, 2001). Interestingly suspension statistics from Ministry of Education (MOE) reports between 1996 and 2002 show that seventy-five percent of schools did not suspend a single student, two per cent of schools were responsible for thirty-five per cent of all suspensions and fifteen per cent for twenty four per cent of all stand downs. Clearly, where you go to school in New Zealand can affect your chances of completing your education without disruption (Hancock \& Trainor, 2004). In light of the above New Zealand suspension statistics, it is possible that some schools are managing to meet students' learning and behavioural needs better than others, or those students likely to need support are not getting into these schools.

\section{Schooling as a process of social production and reproduction}

Thomson (1999) describes a conflict in the range of expectations and mandates schools have set for themselves. Among other things, they are expected to fulfil the potential of each child, ensure children are active tolerant citizens and productive workers, sort and select for higher education and employment, discipline the unruly, and prevent future social mayhem. She argues that the need to sort and select dominates, ensuring that educational advantage is provided for the already privileged. She points out that much research has looked at how kinds of knowledge and pedagogies operate to further alienate certain raced, classed and gendered students. Thomson (1999) advocates for shifting the curriculum focus onto citizenship and social participation and providing all students with the knowledge and skills required for being active in a broader social context.

\section{Inclusion}

New Zealand law requires the provision of the basic right to education to all people aged between five and nineteen years in New Zealand (s3. Education Act, 1989). The prevailing belief is that it is in a child's best interests to be enrolled in a school. National Education Goals (NEGs) are one component of The National Education Guidelines that are defined by s60A of the Education Act, (1989). The NEGs are statements of desirable achievements by the school system, or by an element of the school system. They include equality of opportunity for all New Zealanders, identification and removal of barriers to achievement, identification of students with special needs and the provision of appropriate support for these needs (Ministry of Education, 2004).

In addition to legislation, Article 28 of the United Nations Convention for the Rights Of the Child 1989 (UNCROC), of which New Zealand is a signatory, recognises the rights of the child to education and states that State parties will make primary education compulsory and available to all, and encourage the development of different forms of secondary education, including general and vocational education and make them available and accessible to every child. Article 29 states that education should be directed to the development of the child's personality, talents, and mental and physical abilities to their fullest potential and the development of respect for human rights and fundamental freedoms, and for the principles enshrined in the Charter of the United Nations (Office of the High Commissioner for Human Rights, 2004).

In reality many students find their mainstream schooling interrupted, reduced or even finished as schools struggle to find ways to manage severe behaviour problems (Collin, 2001; Hancock \& Trainor, 2004). Schools find the most difficult students to include are those with emotional and behavioural difficulties (Hayden, 1997). Behaviour should be viewed as a whole-school issue requiring a whole-school solution (Prochnow, 1998; Thomson 1999). Schools can then say they have done their best to meet their obligations to provide all students with an education as per the Education Act (1989) and UNCROC (1989).

\section{How is a whole-school approach defined in the literature?}

A whole-school behaviour approach as described in the literature includes a positive, flexible, comprehensive systems framework developed in consultation with pupils, staff and parents. It is designed to prevent problems through the provision of clear, consistent and agreed systems, policies and procedures (Doig, 2000). It can include a tiered approach, addressing behaviour issues at the school-wide or group/classroom and individual levels (Eber et al., 2002; Hayden, 1997; Nelson et al., 2002; Thomson, 1999). It is most effective when underpinned by a set of principles agreed to and promoted by the school community. The principles of inclusion, belonging, relationship building and collaboration are often referred to in the literature (Doig, 2000; Gaffney et al., 2004; Thomson, 1999). The approach requires a shared vision, goal and commitment to change from the management, staff and students of a school (Doig, 2000; Gaffney, et. al., 2004; Prochnow, 1998). An effective school-wide approach should have the same qualities as an effective teacher, that is, be consistent, firm, clear, caring, organised, enthusiastic and confident (Prochnow, 1998).

Whole-school approaches such as 'Effective Behaviour Support' (EBS) and 'Positive Behavioural Interventions and Support' (PBIS or PBS) are described in the US studies referred to in this review (Eber et al., 2002; McCurdy et al., 2003; Nelson et al., 2002; Sugai \& Horner, 2002).

These school-wide approaches have their roots in applied behaviour analysis (Sugai \& Horner, 2002). They involve careful assessment of the school environment and application of positive behavioural interventions and systems across the school in an attempt to create positive learning and teaching environments and reduce problem behaviours. 
They rely on practices and strategies that are research validated, use team-based problem solving and data-based decision making (Sugai \& Horner, 2002).

Nelson et al., (2002) looked at seven elementary schools who implemented an EBS programme over two years. This involved developing a school wide programme through a consensus building, and participatory process. The programme consisted of five elements: a school wide discipline programme, one to one tutoring in reading, conflict resolution training for students, a video-based family management programme and an individualised, functionbased behaviour intervention plan (primary, secondary and tertiary interventions). Findings from this study showed consistent declines in suspensions, emergency removals and office referrals in participating schools and an improvement in academic achievement across most subjects, except maths (Nelson et al., 2002). A similar project involving implementation of PBS in an ethnically and racially diverse inner-city elementary school also resulted in significant reductions in the overall level of office discipline referrals and student assaults (McCurdy et al., 2003). The US studies have a strong emphasis on a behaviourist approach and while they used a participatory, consensus building process, they made no explicit mention of the importance of relationship building. The important feature seen as critical to programme effectiveness was the comprehensive nature of the approach. This was seen as necessary in order to provide the differing levels of intervention required in a school. The interventions were designed to affect all areas of need (Nelson et al., 2002).

\section{WHAT ARE THE KEY PRINCIPLES THAT MAKE A WHOLE-SCHOOL APPROACH EFFECTIVE?}

The key principles belonging, relationships, and engagement, are closely linked to each other and to behaviour management approaches. It is important to understand the link between these principles and the potential success of a whole school approach to behaviour management.

\section{Belonging}

"Belonging is defined as an individual's sense of being accepted, valued, included and encouraged by others" (Baumeister \& Leary, as cited in Fredericks, Blumenfeld, \& Paris, 2004 p. 80 ).

Osterman (2000) reviewed research on students' sense of acceptance ('belongingness') within the school community. All studies reviewed came to similar conclusions that students' experiences of belonging are linked with positive orientation towards school, class-work and teachers. Students who had a sense of belonging were more likely to show a stronger sense of identity, autonomy, intrinsic motivation, acceptance of authority and acceptance of responsibility to control their own behaviour. The students also showed higher academic engagement and achievement (Osterman, 2000). Conditions in the classroom and the school influence students' feelings about themselves and in turn their experiences of engagement in that environment. Osterman emphasised the importance of developing organisational practices and policies which affect the development of students' sense of community in the school (Osterman, 2000).

\section{Relationships}

The importance of relationships and the value that is placed upon them is a key aspect of establishing a sense of belonging (Certo, et al., 2003). It follows that it is also the key to a successful whole-school behaviour approach (Doig, 2000; Gaffney, et. al., 2004; Parsons, 2002; Rogers, 1995). Establishing positive, supportive and collaborative relationships between staff is an important precursor to examining and improving the relationships between staff and students and between students (Gaffney, et. al., 2004; Rogers, 1995). The principles, which underpin these relationships, are what will have the greatest impact on the culture of the school and, therefore, the experiences that staff and students have. The three schools described by Gaffney et al., (2004) identified respect as the key principal underpinning their approaches. In all three, it was the focus on relationships throughout the school that was the foundation for effective change (Gaffney et al., 2004). No two schools are the same, and they will hold values and beliefs particular to their community. Opportunities for staff to discuss and agree on the values that they hold as a school community is a crucial early step in establishing an effective whole school approach ( Doig, 2000; Gaffney et al., 2004; Parsons, 2002; Prochnow, 1998; Rogers, 1995).

\section{Engagement}

Engagement is strongly linked with having a sense of relatedness or belongingness to a school (Certo et al., 2003; Furrer \& Skinner, 2003; Osterman, 2000). Engagement in the literature refers to active, goal-directed, flexible, constructive, persistent, focused interactions with the social and physical environments' (Furrer \& Skinner, 2003 p. 149). Engagement is a good predictor of long-term academic achievement and school completion (Anderson et al., 2004; Certo et al., 2003; Furrer \& Skinner, 2003). Following a study into children's sense of relatedness and it's link with academic engagement, Furrer and Skinner (2003) concluded that this sense of relatedness played a crucial role in their academic engagement and performance. Building the quality of children's relationships should be a priority for schools (Anderson et al., 2004 ; Certo et al., 2003; Furrer \& Skinner, 2003).

A commitment to positive supportive relationships in a school community leads to a greater sense of belonging or connectedness to that community for staff and students. This in turn is linked to students' sense of engagement which is linked to their academic achievement. When considering effective whole-school approaches to behaviour management, relationships would seem to be at the heart of the matter. 


\section{WHAT ARE THE KEY SYSTEMS THAT MAKE A WHOLE-SCHOOL APPROACH EFFECTIVE? Leadership}

If a whole-school approach is to be effective, there is a need for the leaders of a school to foster caring, supportive, collaborative relationships. Effective leaders demonstrate respect and foster a sense of belonging, celebrate achievement and have a vision for the school they share, model and promote. They value staff and encourage initiative and they use systems which enhance communication (Dinham, Cairney, Craigie, \& Wilson, 1995). Leaders hold the key to building a positive school culture and structure. The leadership of the school principal in deciding change is required as a crucial first step in implementing an effective whole-school approach. They must also have the ability to get "buy-in" from their staff and students (Gaffney et al., 2004).

\section{Effective Teaching}

From students' perspectives, an effective teacher is one who cares about them and has a belief in their ability to learn and achieve (Certo et al., 2003). This is communicated both in their interactions with students and the kind of learning situations they provide. In a study which explored students' level of belonging and engagement in high school by obtaining students perspectives on school, Certo et al. (2003) found that students were more engaged when the school programme provided authentic curriculum and class-work. This included opportunities for discourse, small group work, cognitively challenging work, cooperative learning, participation in decision making and high quality instruction from the teacher (Certo et al., 2003). Students in the study described engaging teachers as those who did not talk too much, allowed students to be actively involved in a learning task, provided opportunities for students to work together, used a variety of instructional techniques and were enthusiastic about the subject matter. Teachers who cared were identified as most effective. Caring teachers were described as "relating to us", "encouraging", and "helpful". Teachers who listened were seen as the most caring (Certo et al., 2003).

In a summary of three studies carried out between 1999-2000 across the primary, secondary (involving Māori and Pasifika students) and tertiary sector (involving Pasifika students), Hawk, Tumana Cowley, Hill and Sutherland (2002) highlighted key attributes that had been consistently identified by students and teachers as characterising an effective teaching/learning relationship. The attributes were empathy, caring, respect, going the extra mile, passion to enthuse and motivate, patience and perseverance, and belief in their ability.

\section{Discipline}

A discipline system which reflects a commitment to positive relationship building will have policies and practices that support a student to take responsibility for their behaviour and learn the skills needed to manage within a school environment (Doig, 2000). There was a reasonable amount of agreement in the literature about what made a discipline system effective. It is important for schools to develop an agreed 'language of discipline' (Rogers, 1995). Schools need to be create clear expectations through discussions with staff and students about desirable school relationships and appropriate behaviour (Doig, 2000; Gaffney et al., 2004; Parsons, 2002; Prochnow, 1998). There is a need for consistent, fair and immediate responses across settings to both appropriate and inappropriate behaviour. Using language and responses that encourages student to take responsibility for their behaviour is important ( Doig, 2000; Gaffney et al., 2004; Rogers, 1995). Providing support for students so they can develop positive relationships and learn to behave appropriately is also an important aspect of an effective discipline system (Prochnow, 1998). Directly teaching students the expectations and routines of the classroom, with opportunities for regular rehearsal, is an important aspect of an effective school-wide approach to discipline. Use of fundamental behaviour management practices such as active supervision, frequent positive contacts and good classroom organisation are also mentioned (McCurdy et al., 2003; Sugai \& Horner, 2002).

\section{Pastoral care}

In a school which is committed to fostering a sense of belonging, students who do not meet expectations for behaviour are not removed but receive support and opportunities to learn how to interact (Gaffney et al., 2004; Parsons, 2002). School ethos has a major impact on how a particular child or behaviour is viewed (Hayden, 1997). Studies have identified that children who have been suspended or excluded are likely to be experiencing a number of stressful events or situations that make it extremely difficult for them to manage a classroom /school environment. These events include family breakdown, violence, being in the care of social services, accidents, a death in the family, unemployment and financial worries. The studies found that excluded children were experiencing on average six such events during the year of their exclusion (Hayden, 1997). It is clear from these studies that most students suspended or excluded are not 'bad' but in need of extra support to enable them to manage their current situation.

Many of the studies reviewed talked about providing support for those students whose behaviour difficulties were not always able to be addressed by the discipline system alone. This support involved providing interventions that addressed the needs of the individual and possibly their family. Interventions included one to one reading programmes, social skills training, parenting programmes, working with other agencies to coordinate support and providing whole school programmes that promoted well-being (Doig, 2000; Eber et al., 2002; Gaffney et al., 2004; McCurdy et al., 2003; Nelson et al., 2002; Thomson, 1990).

\section{Professional development}

Professional development that is designed to support a whole school approach can have many benefits for both 
the staff and the school. In a school that values quality relationships, professional development is given a high priority and staff are given regular opportunities to update their knowledge and reflect on their practice (Doig, 2000). Inspiring curriculum delivery, a range of instructional techniques, and provision of a variety of learning experiences were identified by Certo et al., (2003) as effective ways of engaging students. Clearly it is important that staff set regular opportunities to access training and regularly update and refresh their skills in these areas. It is also important to provide training for staff that enables them to respond consistently and appropriately to severe or difficult behaviour (McCurdy et al., 2003; Prochnow, 1998). The literature describes some of the benefits of professional development for staff, such as beginning to use a shared language, having a better understanding of key concepts, and greater motivation and enthusiasm (Doig, 2000; Parsons, 2002; Prochnow, 1998). Osterman (2000) points out that organisational research over the last few decades has identified collegiality as one of the more important characteristics influencing teachers' commitment, sense of efficacy and performance. The interaction and dialogue central to the notion of collegiality can lead to personal and professional learning among teachers. Again, if the underpinning principle is one of building relationships, the professional development provided can enable staff to form collaborative and supportive professional relationships.

\section{IS THE INVOLVEMENT OF STUDENTS AND IMPORTANT} ASPECT OF A WHOLE-SCHOOL BEHAVIOUR APPROACH?

Many of the articles describing the implementation of effective whole-school behaviour approaches talk about the involvement of students as being a key aspect of their success (Doig, 2000; Gaffney et al., 2004; Thomson, 1999). This involvement can be as simple as asking a group of students why they are always in the withdrawal room and then including them in planning a solution, or asking a student intending to leave school early what the school can do to make them want to continue their education (Thomson, 1999). Again, a commitment to fostering a sense of belonging and quality relationships enables a school to approach such issues in a student-centred way.

Gaffney et al., (2004) found that schools involved students in a variety of ways including training peer mediators, training all students in peer mediation skills, involving students in the development of school rules and classroom charters, and conducting safety audits amongst students. The students spoken with in all three schools had a good understanding of the school and classroom rules and the consequences for inappropriate behaviours.

\section{PRINCIPLES AND SYSTEMS - A SUMMARY}

There is a link between whole-school approaches and a reduction in suspensions and office referrals and an increase in academic achievement (Nelson et al., 2002). The literature also establishes a clear link between belonging, engagement, and achievement (Certo et al., 2003; Osterman, 2000).
In the words of Thomson, "structures and culture are mutually constructed" (Thomson, 1999, p. 10). If a wholeschool behaviour approach is to be effective, it must increase the level of engagement for all of its students. For a school to be able to foster a sense of belonging in its staff and students there is a need for commitment to building positive supportive relationships (Certo et al., 2003; Doig, 2000; Gaffney et al., 2004; Osterman, 2000; Parsons, 2002). This commitment must underpin systems such as leadership, professional development, discipline, pastoral care and valuing diversity in order to prevent behaviour difficulties and increase students' sense of belonging and therefore engagement and achievement.

\section{CONCLUSION}

An effective whole-school approach requires the commitment and shared vision of an entire school community. Creating a community that fosters belonging begins with strong leaders who can bring staff together to examine the quality of the relationships in their school in a safe and effective way. Systems must reflect the shared vision held by the school. To be effective, this vision must begin with a commitment to positive and supportive relationships. This requires committing the time and space needed to enable staff to develop a shared vision through discussion, debate and shared professional development. This should be facilitated by the leaders, driven by the staff and reflect the needs of the whole school community.

If all students are to experience a sense of belonging and inclusion in our schools there must be a shift in the way that schools respond to severe and challenging behaviour. A commitment to all students who belong to a school community regardless of their circumstance could provide a different starting point for addressing unwanted behaviours. This perspective may allow for solutions, that support and include the student while working to eliminate their more inappropriate behaviours.

\section{REFERENCES}

Anderson, A., Christenson, S., \& Lehr, C. (2004). Check and connect: The importance of relationships for promoting engagement with school. Journal of School Psychology, 42(2), 95-113 - Volume.

Certo, J., Cauley, K., \& Chafin, C. (2003). Students' perspectives on their high school eperience. Adolescence, 38(152), 705-724.

Collin, G. (2001). Suspended when will they ever learn. Childrenz Issues, 5(1), 17-22.

Dinham, S., Cairnney, T., Craigie, D., \& Wilson, S. (1995). School climate and leadership: research into three secondary schools. Journal of Educational Administration, 33(4), 36-58.

Doig, C. (2000). Quality the Richmond way: Developing a successful behaviour management programme. Wellington: New Zealand Council for Educational Research. 
Eber, L., Sugai, G., Smith, C., \& Scott, T. (2002). Wraparound and positive behavioral interventions and supports in the schools. Journal of Emotional and Behavioral Disorders, 10(3), 171-180.

Fredericks, J., Blumenfeld, P., \& Paris, A. (2004). School engagement: Potential of the concept, state of the evidence. Review of Educational Research, 74(1), 59-96.

Furrer, C., \& Skinner, E. (2003). Sense of relatedness as a factor in children's academic engagement and performance. Journal of Educational Psychology, 95(1), 148-162.

Gaffney, M., McCormack, J., Higgins, N., \& Taylor, N. (2004). Improving school culture: What we learned from three primary schools. Kairaranga, 5(2), 36-43

Hancock, J. \& Trainor, C. (2004). Ensuring consistency with the Education Act 1989:In a child's best interest. Childrenz Issues, 8(1), 35-49.

Hawk, K., Tumama Cowley, E., Hill, J. \& Sutherland, S. (2002). The importance of the teacher/student relationship for Māori and Pasifika students. SET, 3, 44-49.

Hayden, C. (1997). Children excluded from primary school: Debates, evidence, responses. Buckingham: Open University Press.

McAdam, E., Lang, P. (2003). Working in the worlds of children: Growing, schools, families, communities through imagining. The International Journal of Narrative Therapy and Community Work(4).

McCurdy, B. L, Mannella, M., Eldridge, N. (2003). Positive behavior support in urban schools. Journal of Positive Behavior Interventions, 5(3), 158-170.

Ministry of Education. (2004, April 8) The National Administration Guidelines (NAGs). Retrieved May 252004 from http://www.minedu.govt.nz/print_doc.cfm?layout=doc ument\&documentid $=8187 \&$ inde...

Nelson, J. R., Martella, R. M., \& Marchand-Martella, N. (2002). Maximising student learning: The effects of a comprehensive school-based programme for preventing problem behaviors. Journal of Emotional and Behavioral Disorders, 10(3), 136-148.

Oerlemans, K., \& Jenkins, H. (1998). There are aliens in our school. Issues in Educational Research, 8(2), 117-129.

Office of the High Commissioner for Human Rights. Convention on the Rights of the Child. Retrieved August 1 2004 from http://www.unhchr.ch/html/menu3/b/k2crc.htm

Osterman, K. F. (2000). Students' need for belonging in the school community. Review of Educational Research, 70(3), 323-364.

Parsons, L. (2002). Current trends in the management of emotional and behavioural difficulties. In B. Rogers (Ed.), Teacher leadership and behaviour management (pp. 102-112). London: Paul Chapman Publishing.
Prochnow, J. E. (1998). Creating a school-wide culture for managing difficult student behaviour. NZ Principal, 13(1), 23-24.

Rogers, B. (1995). Behaviour management: a whole-school approach. Gosford: Scholastic Australia Pty Limited.

Sugai, G. \& Horner, R. (2002). The evolution of discipline practices: school-wide positive behavior supports. Child \& Family Behavior Therapy, 24(1/2), 23-50.

Thomson, P. (1999). Against the odds: Developing school programmes that make a difference for students and families in communities placed at risk. Childrenz Issues, 3(1), 7-13.

Wentzel, K. (1999). Social influences on school adjustment: Commentary. Educational Psychologist, 34(1), 59-69.

\section{PROFILE OF AUTHOR}

Bridget Scott is a Special Education Advisor working for Group Special Education in Christchurch. In this role she works to support the needs of students with both severe behaviour difficulties and ongoing resourcing needs. Previously she has worked as a teacher for the Youth Education Service, a programme run by Group Special Education for students from Years 9-10. She also taught for six years in a number of inner London primary schools including two years in a unit for students for communication disorders and one year in a school for students with moderate to high needs. 